\title{
Pedagogia e/com arte: os Actividários de Ricardo Henriques e André Letria
}

\section{Pedagogy and/with art: the Actividários by Ricardo Henriques and André Letria}

\author{
Sara Reis da Silva \\ Universidade do Minho
}

\begin{abstract}
Resumo
Sistema literário criativo, fértil e experimental, quanto à palavra e ao grafismo, a edição para a infância integra objectos estéticos dos três modos literários seminais (a narrativa, a lírica e o drama) e dos seus respectivos (sub)géneros (o conto de autor, ilustrado ou em forma(to) de álbum narrativo, por exemplo), bem como outros com uma configuração híbrida e de difícil tipificação, como os "actividários" ("actividades + abecedários"). Mar e Teatro, de Ricardo Henriques e André Letria, congregam estratégias do dicionário e a função metalinguística, com actividades lúdicas, do domínio das ciências experimentais ou das expressões plástica, dramática ou corporal.

Palavras-chave: literatura para a infância, álbum, livros de actividades, arte, conhecimento pedagógico.
\end{abstract}

\begin{abstract}
Creative, fertile and experimental literary system, in words and in graphic, publishing for children integrates aesthetic objects of the three seminal literary modes (narrative, poetry and drama) and their respective (sub)genres (short stories, illustrated or in picturebook format), as well as others with a hybrid configuration and difficult to typify, such as "actividários" ("activities + ABCbook"). Mar and Teatro, by Ricardo Henriques and André Letria, congregate strategies of the dictionary and the metalinguistic function, with ludic activities, of the domain of the experimental sciences or of the plastic, dramatic or corporal expressions.

Keywords: Children's literatura, picturebook, workbook, art, pedagogical knowledge.
\end{abstract}

\section{Introdução: livros e literatura para a infância}

Sistema literário reconhecidamente criativo, em visível expansão e muito experimental, tanto no que diz respeito à componente verbal, como no que concerne ao domínio visual e/ou gráfico, a escrita e/ou a edição de potencial recepção infantil, consensualmente reconhecida como detentora de uma «grande influência social e educacional» (Hunt, 201: 43), integra objectos estéticos tão diversos como os que se situam nos três modos seminais da literatura (a narrativa, a lírica e o drama), bem como em muitos dos seus respectivos géneros e subgéneros (como o conto de autor, ilustrado ou em forma(to) de álbum narrativo, por exemplo), ou como outros que apresentam uma configuração híbrida e de difícil tipificação até pelos próprios mecanismos gráficos que são, cada vez mais, integrados e ponderados na sua avaliação/análise. Com efeito, e na linha do que preconiza Van der Linden, por exemplo, relativamente aos livros ilustrados ou aos álbuns, tem sido cada vez mais difícil, senão «impossível» (Linden, 2007: 26) fixar uma tipologia destas produções: «On différencie souvent les albums entre fictions et documentaires, affirmant ainsi que les livres proposent soit des récits, soit des connaissances. Or, le documentaire (...) emprunte souvent la forme du récit pour apporter à l' enfant des informations. (...) Une autre distinction pourrait être opérée entre ouvrages fonctionnels et ouvrages d' expression artistique et littéraire, mais là encore elle n'est pas valable puisque les livres éducatifs ou dit "de concept" (abécédaires, numéraires, etc.) relèvent bien souvent d'un travail de création original, qu'il soit plastique ou poétique.» (idem, ibidem: 26). Na mesma linha, Teresa Duran lembra que «Em medio de esta eclosión se produce una confusión importante provocada, sin lugar a dudas, por la novedad del producto - en cuanto a la definición y denominación de los nuevos materiales.» (Duran, 2002: 80-81).

A verdade é que, cada vez mais, livros ficcionais ou não ficcionais, profusamente ilustrados, que tematizam uma pluralidade de tópicos, que ostentam, por exemplo, abas para puxar ou pull-the-tab, tiras para desvendar, segmentos pop-up, orifícios com formatos diversos, mecanismos sonoros, texturas ou cheiros, por exemplo, proliferam quantitativa e qualitativamente no mercado editorial nacional e internacional. Menos abundantes são, todavia, os volumes nos quais, com uma composição gráfica de qualidade, se procura associar a veiculação de conteúdos e, portanto, o intuito (in)formativo, assente num discurso didáctico e uma proposta de actividades que constituem um desafio lúdico e que, por vezes, até, oferecem segmentos ficcionais ou nos quais se observa a presença de um discurso (que toca o) literário.

\section{Livros formativos didácticos e livros formativos literários}

É o que sucede, por exemplo, não apenas com os abecedários e os numerários literários, formas editoriais com uma vasta tradição, de ampla difusão e de reconhecido sucesso, mas também com um outro tipo de publicação, mais recente e ainda escassamente analisado: os "actividários". Com efeito, nestes, mesclam-se discursos plurais (ou seja, a ilustração, alguns trechos de texto literário, vários segmentos de teor informativo e, 
ainda, um discurso didáctico, com o qual se pretende que o destinatário extratextual construa aprendizagens significativas, a partir de exercícios distintos) que conformam um todo manifesta e simultaneamente estético e pedagogógico.

Num apelativo "entre-caminho", no qual se cruzam características próprias dos livros formativos didácticos e dos livros formativos literários, estes objectos apresentam a informação organizada a partir da linguagem e ordenada segundo a ordem alfabética (Garralón, 2015: 161). Almejando a objectividade e conjugando as funções metalinguística e informativa da linguagem, estas obras evidenciam, ainda e também um carácter estético, por exemplo, pela evocação de narrativas ou de trechos ficcionais e, assim sendo, supõe-se igualmente a presença da função poética. Além disso, é notória a intencionalidade didáctica e pedagógica materializada na proposta de uma considerável plêiade de actividades situadas em domínios do saber ou em disciplinas muito diversas. Referimo-nos, por exemplo, a sugestões relativas à expressão corporal e física, ao movimento e drama ou à expressão visual e plástica. De facto, a interdisciplinaridade é, neste género de volumes, um dos aspectos mais relevantes, verdadeiramente estruturantes, auxiliando, de certa maneira, a consolidar conhecimentos propostos e transmitidos com o objectivo da aprendizagem ou da (in)formação. A sequencialização de conteúdos norteada pelo alfabeto serve, portanto, o seu propósito fundamental: informar, explicar, descrever e ensinar aspectos do mundo real, a partir de uma comunicação verbo-icónica eminentemente lúdica, intentando-se, pois e simultaneamente, entreter ou divertir.

O cruzamento de aspectos factuais e de segmentos ficcionais proporciona uma forma de aprendizagem muito estimulante, como se poderá constatar no contacto com e na análise dos volumes que constituem o corpus textual seleccionado para este breve estudo: Mar e Teatro, de Ricardo Henriques e André Letria.

\section{Os actividários Mar e Teatro, de Ricardo Henriques e André Letria}

Os actividários co-assinados por Ricardo Henriques e André Letria ostentam um conjunto de singularidades que os distinguem de qualquer volume de similar categoria editado em Portugal e/ou com autoria portuguesa. Rompendo com modelos, a partir, na verdade, do próprio cruzamento ou mistura de formas e géneros, em concreto do abecedário, aqui substantivado e expandido, tocando a configuração de um dicionário, e do livro de actividades, Mar (Pato Lógico, 2012) e Teatro (Pato Lógico, 2015) - cada um deles, como o título propõe cataforicamente, construído a partir de um núcleo temático clara ou objetivamente fixado apresentam a definição/explicação de mais de duas centenas de vocábulos, pertencentes aos campos lexicais em pauta, aos quais se juntaram quase uma centena de propostas de actividades ou desafios.

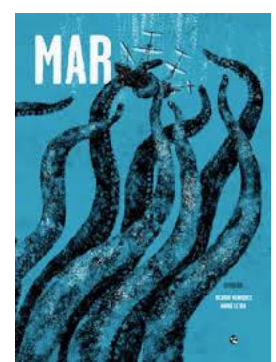

Figura 1. Capa de Mar.

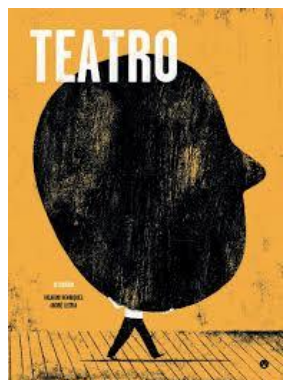

Figura 2. capa de Teatro.

Estas actividades revestem-se de um evidente carácter imaginativo, destacando-se pela sua criatividade (vide, por exemplo, Henriques e Letria, 2015: 32-32; 55).

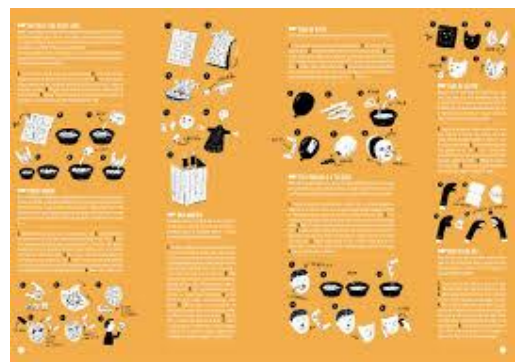

Figura 3 . Página dupla de Teatro

Precisão, exactidão e autenticidade, que, neste caso, decorrem naturalmente de um sério trabalho autoral de investigação, sistematização e síntese, são as marcas expectáveis e, de facto, observáveis nestas obras. Nestas, também se nota um discurso simples e vivo, que se pretende próximo do potencial destinatário (aliás, esta tentativa de proximidade é bem visível em segmentos como na entrada "Ufa!" presente na págima 58 de Teatro), aspecto reflectido em expressões como «Grande Pinta» (Henriques e Letria, 2015: 43), e que apela abertamente à sua acção. Formas verbais no modo imperativo e seguidas de exclamação, como «Respira!» (idem, ibidem: 42) ou «Disparata» (idem, ibidem: 43) revelam o desafio actancial que o texto vai oferece.

Uma nota, ainda, para assinalar o facto destas obras, sendo livros factuais ou fundamentalmente alicerçados no mundo empírico ou histórico-factual, oferecerem também breves trechos de cariz ficcional, bastante estimulantes do ponto de vista da imaginação e da criatividade.

Graficamente, as obras em análise possuem um formato ou uma dimensão considerável, reflectindo uma especial ponderação técnico-compositiva, designadamente pela conciliação de texto sequencializado a partir do próprio alfabeto, colocado em 
colunas, com a disposição, em paralelo, de caixas de texto predominantemente rectangulares, mas também, por vezes, até circulares (Henriques e Letria, 2015: 49), que apresentam alusões a pormenores ou curiosidades, por exemplo, e ainda de esquemas muito elucidativos (idem, ibidem: 16-17), imagens legendadas (idem, ibidem: 46 e 47; Henriques e Letria, 2012: 36-37) ou de ilustrações que exemplificam e esclarecem com particular eficácia (Henriques e Letria, 2015: 45).

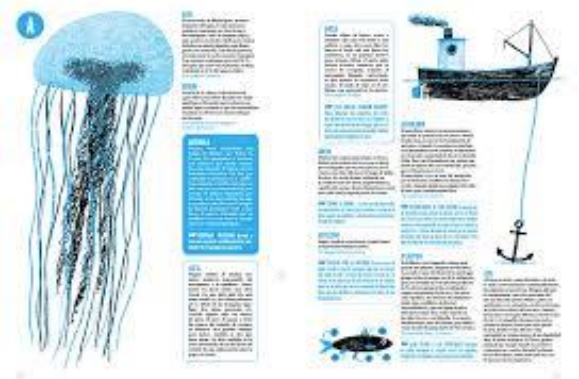

Figura 4. Página dupla de Mar.

O design da página, na qual coexistem texto e ilustração, afigura-se, portanto, equilibrado e sensato. Os jogos visuais consubstanciam-se, ainda, a partir da oscilação cromática, muito embora se constate uma relativa economia a essa nível, na medida em que o azul e o amarelo alaranjado, para o Mar e para Teatro, respectivamente, são as cores eleitas, surgindo conjugadas apenas com o branco e os tons de cinza.

Além disso, é notória a presença de um conjunto significativo de ilustrações muito imaginativas (idem, ibidem: 65), dispostas diversamente nas páginas, quer sejam em página singular, quer em páginas duplas (idem, ibidem: 58-59). Exemplares são, por exemplo, alguns frisos ou tiras visuais (idem, ibidem: 20-21, 50-51, 70-71) ou, ainda, algumas imagens representativas de figuras humanas (Henriques e Letria, 2012: 34, 52; Henriques e Letria, 2015: 35, 49, 56) ou de alguns objectos e instrumentos (Henriques e Letria, 2012: 9, 14) associados às temáticas tratadas.

Mar e Teatro fecham de forma diversa, mas igualmente estimulante: no primeiro caso é apresentada uma «Lista das excluídas indignadas» (Henriques e Letria, 2012: 56), segmento pontuado de humor; no segundo caso, inclui-se um excerto de Ensaios I, aqui intitulado «O pintor no teatro» (Henriques e Letria, 2015: 72), da autoria do modernista Almada Negreiros.

Em suma, a configuração destes dois volumes permite-nos assinalar uma certa desformalização do livro e da própria veiculação de conteúdos que podem ser obviamente como formais, mas que ganham aqui uma película artística, unindo-se a propostas desafiadoras de universos tão distintos como o cinema, a música, a pintura ou a expressão visual e plástica, a dramatização, a própria escrita criativa, entre outros.

\section{Considerações finais}

Em Mar e Teatro (Pato Lógico, 2015), actividários ("actividades + abecedários") da autoria de Ricardo Henriques e André Letria, que compuseram o corpus textual e exemplificativo do nosso estudo, observa-se, assim, a congregação de estratégias próprias do dicionário e, portanto, a própria função metalinguística, a par do recurso a propostas de actividades relativas tanto aos domínios isotópicos que os títulos cataforicamente testemunham, o mar e o teatro, como a áreas do conhecimento como as ciências experimentais, a expressão visual e/ou plástica, a expressão dramática ou corporal, entre outras. Com efeito, trata-se de dois volumes que exemplificam exemplarmente o seguinte ponto de vista de Peter Hunt: «Supor que a literatura infantil seja de algum modo homogênea é subestimar sua diversidade e vitalidade» (Hunt, 2010: 49). Desta feita, pela mão de Ricardo Henriques e André Letria, estes inovadores objectos, desafiadores também pelo seu hibridismo, situam-se no domínio não apenas da «educação sensorial», como preconiza Maria Montessori (Torrado, 2002: 17), mas também da «educação pela arte» (Rodari, 2017: 227), pilares de uma formação estética e ética, de uma integral construção humana. Estas obras, por conseguinte, poderão proporcionar a ampliação de conhecimentos e experiências sobre realidades distintas, o desenvolvimento de estratégias de compreensão, a conformação de uma cultura artística e literária e, ainda, a descoberta das possibilidades lúdicas da leitura e do próprio livro. Em suma, estes dois actividários representam, pois, sintomas de que há, na edição portuguesa, ainda tão carente de volumes similares aos analisados, a feliz preocupação em oferecer aos leitores mais novos, no contacto, com o livro, um «tipo de experiência integral» (Rodari, 2017: 227).

\section{Referências}

Duran, T. (2002). Leer antes de leer. Madrid: Anaya. Garralón, A. (2015). Ler e Saber. Os livros informativos para crianças. São Paulo: Editora Pulo do Gato.

Garralón, A. (s./d.). «Ficção e informação. Tendências nos livros informativos» - disponível em http://www.revistaemilia.com.br/mostra.php?id=126 (consultado no dia 26/02/2017) (Artigo originalmente publicado na Revista CLIJ, $\left.\mathrm{n}^{\circ} 166\right)$.

Henriques, R. \& Letria, A. (2012). Mar. Lisboa Pato Lógico.

Henriques, R. e Letria, A. (2015). Teatro. Lisboa Pato Lógico.

Hunt, P. (2010). Crítica, teoria e literatura infantil. São Paulo: Cosac Naify.

Linden, S. V. D. (2007). Lire l' album. Le Puy-en-Velay: L'atelier du poisson soluble.

Rodari, G. (2017). Gramática da Fantasia. Matosinhos: Faktoria de Livros ( $1^{\mathrm{a}}$ ed. 1973).

Torrado, A. (2002). Da Escola sem Sentido à Escola dos Sentidos. Lisboa: Caminho ( $3^{\mathrm{a}}$ ed.). 